\title{
Erratum to: Petrol filling workers as biomonitor of PAH exposure and functional health capacity in resource-limited settings of city Rawalpindi, Pakistan
}

\author{
Audil Rashid $^{1} \cdot$ Shu Tao $^{2} \cdot$ Ikhtiar Uddin $^{1} \cdot$ Atif Kamal $^{1}$
}

Published online: 19 July 2017

(C) Springer-Verlag GmbH Germany 2017

Erratum to: Environ Sci Pollut Res

DOI 10.1007/s11356-017-9372-Z

The original publication of this paper contains an error.

The correct name of the $2^{\text {nd }}$ Author is Shu Tao.

The online version of the original article can be found at http://dx.doi.org/ 10.1007/s11356-017-9372-z

\footnotetext{
Audil Rashid

audil@uaar.edu.pk
}

1 EcoHealth Research Group, Department of Environmental Sciences, Pir Mehr Ali Shah, Arid Agriculture University, Rawalpindi 46300, Pakistan

2 College of Urban and Environmental Sciences, Peking University, Beijing 100871, China 